This item was submitted to Loughborough's Research Repository by the author.

Items in Figshare are protected by copyright, with all rights reserved, unless otherwise indicated.

The advantages of information management through building information modelling

PLEASE CITE THE PUBLISHED VERSION

http://dx.doi.org/10.1080/01446193.2013.777754

PUBLISHER

(c) Taylor \& Francis

VERSION

AM (Accepted Manuscript)

LICENCE

CC BY-NC-ND 4.0

REPOSITORY RECORD

Demian, Peter, and David Walters. 2019. "The Advantages of Information Management Through Building Information Modelling”. figshare. https://hdl.handle.net/2134/12185. 
This item was submitted to Loughborough's Institutional Repository (https://dspace.lboro.ac.uk/) by the author and is made available under the following Creative Commons Licence conditions.

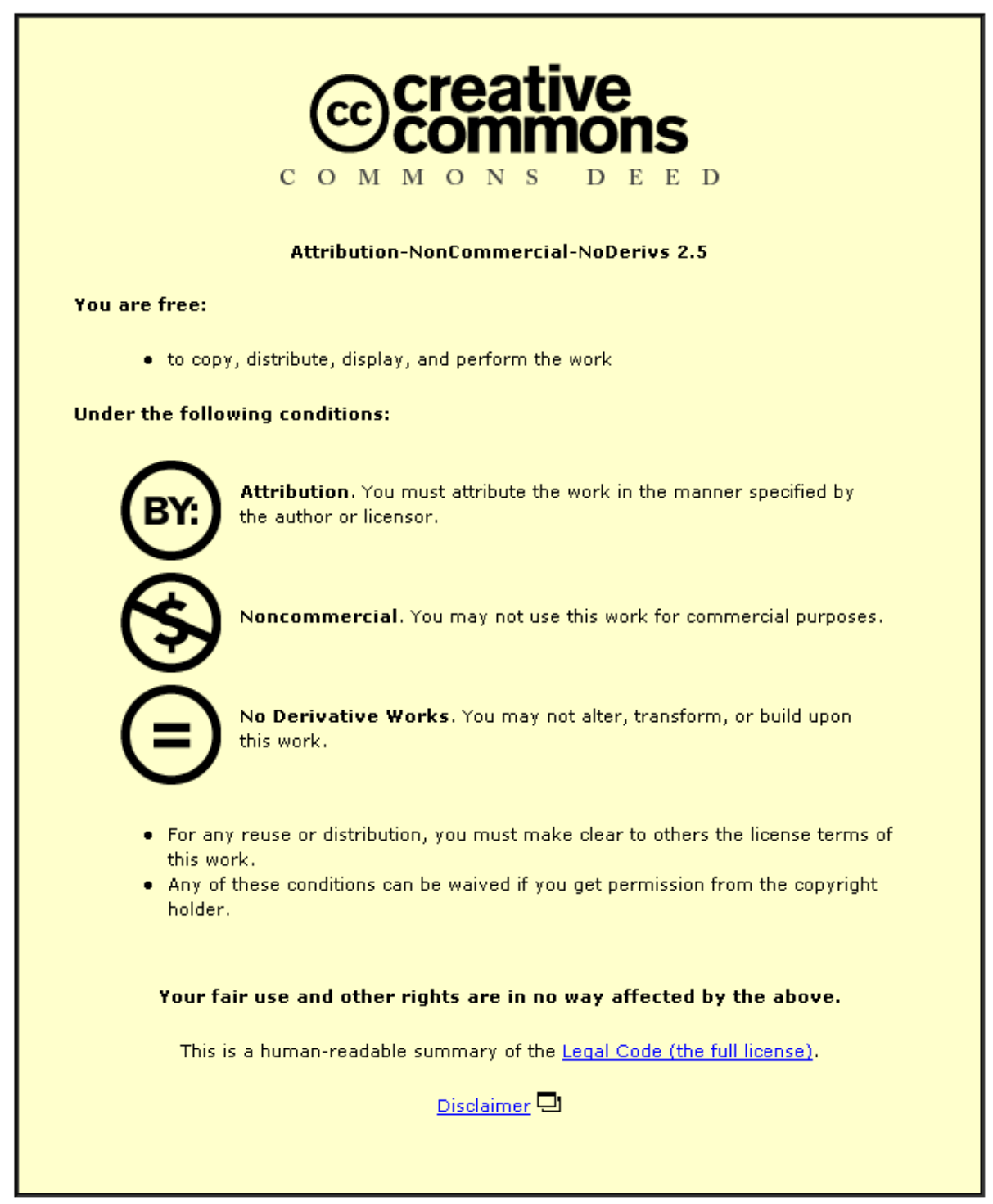

For the full text of this licence, please go to: http://creativecommons.org/licenses/by-nc-nd/2.5/ 
Peter Demian \& David Walters (2013): “The advantages of information management through building information modelling", Construction Management and Economics, DOI:10.1080/01446193.2013.777754

\title{
The Advantages of Information Management through Building
}

\section{Information Modelling}

\begin{abstract}
As Building Information Modelling (BIM) is positioned by governments and construction professionals as a solution to the problems in the construction industry, research is needed into the benefits BIM actually confers. The focus here is on the effectiveness of BIM as a medium for communicating information within a construction team. A case study of an off-site precast concrete fabrication facility was conducted. At the time of the study, the facility was supplying precast units for four public sector projects, and using four information management systems: email, a construction project extranet tool, an Enterprise Resource Planning system and a new BIM-based system. The flow of information through the four media was measured and visualised as the projects progressed. This quantitative measurement of information flow was combined with qualitative data from interviews with facility staff. It was found that the introduction of the BIM-based system diverted information flow through the building model and away from the extranet system. The use of email was largely unaffected. that BIM allowed considerably more accurate, on-time and appropriate exchange of information. It is concluded it is possible to quantify some of the benefits of BIM to information management. This research paves the way for future research into the management of more construction project information linked more closely to building models.
\end{abstract}

\section{Keywords}

Building Information Modelling, Information Management, Construction Information 
Peter Demian \& David Walters (2013): "The advantages of information management through building information modelling", Construction Management and Economics, DOI:10.1080/01446193.2013.777754

\section{Introduction}

The emergence of Building Information Modelling (BIM) warrants a fresh look at information flows and communication in building design and construction. A review of historical data (Teicholz 2001) showed that while productivity in all non-farming industries had more than doubled over a 40-year period, construction productivity had fallen by around 5\%. Another study suggests that communication and data handling accounts for between $75 \%$ and $90 \%$ of a project manager's time in the construction industry (Fisher \& Yin 1992). Although comparisons across different industrial sectors are difficult to make and interpret, such published findings suggest that the recent innovations in information management and the level of collaboration seen in other industries have not yet been fully realised in construction. Even within construction, a more recent study (Eastman and Sacks 2008) implies that innovations such as BIM are facilitating productivity gains in offsite (more than in onsite) construction.

Whilst there is a consensus that construction is a low-performing sector in terms of innovation (Sexton and Barrett 2003, Pries and Janszen 1995, Slaughter 1998), the reasons for this remain unclear; Reichstein et al. (2005) identify six factors, unique to the industry, affecting the UK construction industry's ability to innovate.

Those are the:

- $\quad$ Liability of projects

- $\quad$ Liability of immobility

- $\quad$ Liability of uncertain demand

- $\quad$ Liability of smallness

- Liability of separation

- $\quad$ Liability of assembly

These liabilities go some way to explaining why concepts from mass production and lean thinking have never been particularly relevant to construction (Winch 2003), but ideas centred on information management systems bear significantly more relevance to the project-driven nature of construction. In particular, recent and ongoing developments in BIM hold the potential to bring significant benefits to the transfer, storage and access of construction project information (Eastman et al. 2008, Huang et al. 2009).

The aim is to measure the benefits and challenges involved in the application of a BIM-based system for construction information management, through analysis of primary data collected at an off-site precast 
Peter Demian \& David Walters (2013): “The advantages of information management through building information modelling", Construction Management and Economics, DOI:10.1080/01446193.2013.777754 concrete fabrication facility. This is achieved by measuring the volumes of information and workflow rates through BIM and other media. The off-site precast concrete fabrication facility was a subsidiary of the large general contractor, but was run autonomously. The two organisations had independent information management platforms, but the close relationship between the two facilitated some degree of coordination between the various information systems, and allowed measurements to be taken for the purpose of this research.

\section{Literature Review}

\subsection{Construction Information Management}

A number of studies have highlighted both the extent (Hendrickson and Au 2003) and importance (Howell 1999) of information management activities in construction. Despite significant research and investment, studies formulating and applying new financial models to large-scale construction projects in the US have shown that construction organisations are largely dissatisfied with their IT investments (Pena-Mora et al. 1999), from the perspective of managers monitoring return on investment. Jacobsson and Linderoth (2010) find in a Swedish case study that the transient nature of project teams ("temporary organisations") limits the drive to deploy information management technologies. They report (2012) that the end users of these technologies are generally "fairly satisfied". Those studies seem to lean more towards qualitative data and user perceptions as a research approach, in contrast to the research presented here which favours quantitative data and numerical measurement of information flow.

In trying to propose new technologies and frameworks for information management, researchers have found that information management and exchange within construction typically still takes place manually, with individuals or organisations reformatting and manually distributing information (Dawood et al. 2002), normally on a document level (Anumba et al. 2008). This leads to wasted time and cost through data loss when information is exchanged or converted, inefficiencies through rework, further wasted time spent identifying the useful information in a document (Anumba et al. 2008), and the late, incomplete, uncoordinated and/or inappropriate exchange of information. The fragmented nature of the construction industry frequently leads to incompatibilities in semantics, process and software between collaborating organisations (clients, designers, contractors, suppliers, and so on), amplifying the waste mentioned above (Anumba et al. 2008, Abukhder and Munns 2005). 
Peter Demian \& David Walters (2013): "The advantages of information management through building information modelling", Construction Management and Economics, DOI:10.1080/01446193.2013.777754

Taken cumulatively, it is therefore clear that the key requirement in any improved information management system is the co-ordination of information exchange. Dawood et al. (2002) discuss the challenges involved in creating a system that will 'meet the different views and needs of the multiple professional disciplines involved in the construction process'. BIM is well positioned to meet these needs in construction. Sacks et al (2010) have identified the synergies between the principles of BIM and lean construction, and observed that information can be managed according to lean principles. However little work is published specifically on measuring information flows through BIM to evaluate its impact on the challenge of information exchange and co-ordination.

\subsection{What is Building Information Modelling?}

BIM means different things to different people and in different contexts. BIM is generally 'a modelling technology and associated set of processes to produce, communicate and analyse building models' (Eastman et al. 2008). BIM builds upon the concepts of 3D modelling by incorporating non-graphical object data into the model. Many studies define BIM through the benefits it confers, including parametric modelling (Huang et al., 2009), detailed building analysis (Krygiel et al. 2008), 4D programming whereby the construction programme is linked into the building model (Mahalingam et al. 2010), 5D modelling, whereby cost data is also integrated into the building model (Goedert and Meadati, 2008) and more generally nD modelling (Marshall-Ponting and Aouad, 2005). For the purposes of the research presented here, BIM is defined as a comprehensive accumulation of information (including documents) about the design, construction and operation of a building, anchored to a geometric (2D/3D) model of the building (as such a model emerges). The fundamental subtlety that makes a building model a BIM model (rather than, say, a CAD model) is the object orientation and the symbolic information linked to the geometry. A 3D shape might have the symbol "column" labelling it, enabling other information systems as well as human users to use that geometric information as a building object more effectively.

BIM now constitutes a set of maturing technologies and work processes. BIM research has been widely published in Construction Management and Economics (Fox and Hietanen, 2007, Li et al., 2011) and elsewhere. BIM technology has already delivered benefits in building construction (Giel and Issa, 2010; Aranda-Mena et al., 2008; Leicht and Messner, 2008; Lee et al 2012). However no studies could be found 
Peter Demian \& David Walters (2013): “The advantages of information management through building information modelling", Construction Management and Economics, DOI:10.1080/01446193.2013.777754

which attempt to measure the volume of information flowing through a BIM model as a communication medium, compared to other media.

\subsection{Barriers to BIM Adoption}

Whilst the documented benefits are widespread and significant, sizeable research effort has also been expended identifying the current barriers to implementing BIM more extensively. Eastman, et al (2008) highlight that 'BIM is not a thing or a type of software but a human activity that ultimately involves broad process changes in construction.' In order to gain the full benefits of BIM, these changes must be made gradually and within multiple collaborating organisations, with decisions regarding the implementation made on a project-by-project basis.

A broad category of process changes relates to the significant volume of training required. A relatively steep learning curve is associated with a switch to BIM technologies, with the first employees to undergo training likely to be unproductive, especially as they will need to customize tools for the company's own uses (Krygiel et al. 2008).

From a contractual standpoint, the increased collaboration between organisations employing BIM means an increased entwining of fortunes. Current contract terms do not allow for this collective responsibility, nor do current tools provide enough support for tracking and monitoring changes. The closer collaborative working facilitated by BIM also highlights the problem of interoperability. In an evaluation of the interoperability issue in BIM, Grilo and Jardim-Goncalves (2010) identify interoperability as a major barrier to BIM adoption. In the US, studies suggest that inadequate interoperability within the capital facilities industry costs $\$ 15.8$ billion each year (Gallaher et al., 2004). Standards are common throughout the construction industry already (Björk and Laakso, 2010), but the implementation of BIM requires the development of new standards, particularly those specifically for construction.

\subsection{Attempts to Measure Information Flow}

Despite numerous research efforts identifying the benefits and barriers to the use of BIM, relatively few studies have attempted to measure these in use. This study adapts the measurement techniques built by Tribelsky and Sacks (2010), who took the concepts of lean thinking (Womack, Jones and Roos, 1990) and leveraged them as a system of measuring and quantifying information flow in the detailed design phase of 
Peter Demian \& David Walters (2013): “The advantages of information management through building information modelling", Construction Management and Economics, DOI:10.1080/01446193.2013.777754 construction projects. Based on Hicks' (2007) definition of waste within information management, the study analysed information flow during the design development phase of 14 construction projects, utilising 7 indices; action rate, package size, work in process, batch size, development velocity, bottlenecks, and rework.

\section{Method}

\subsection{Methodology}

This research spans construction management and information management, a young field deserving careful choice of research method(s) to address a particular type of research question. Researchers in information systems (Fitzgerald and Howcroft 1998) have taken a humorous look at the tension between "hard" and "soft" research in that field. Standard texts on construction research methods (e.g. Fellows and Liu 2003) often implicitly map the friction between hard and soft research to the distinction between collecting and analysing quantitative versus qualitative data. As part of measuring the benefits and challenges of applying BIM, the research reported here attempts to quantify information flows through BIM and other systems. This suggests taking a quantitative, positivist approach and is reflected in the method adopted of measuring and visualising information flows. Still, it is recognised that such quantities are context dependent; the world is sometimes best understood through an interpretivist lens, whereby reality is socially constructed. The measurements of information flow were therefore accompanied by interviews with staff from the fabrication facility to allow a holistic consideration of the projects studied, the systems used for information management and the relationship between the fabrication facility and the other project stakeholders.

\subsection{Primary Data}

A mixed methods approach was adopted, combining quantitative measurement of actual information flows with qualitative recordings of perceptions of the quality of information flow. Measurement data consisted of information flow logs exported from the four primary information systems used by an off-site fabrication facility in the UK. This quantitative data was supplemented with interviews with five employees from the business. Four case study building construction projects were selected:

1. Project $1-$ a university project in the South-East of England, requiring the fabrication and delivery of 795 units. 
Peter Demian \& David Walters (2013): “The advantages of information management through building information modelling", Construction Management and Economics, DOI:10.1080/01446193.2013.777754

2. Project $2-$ a Building Schools for the Future scheme project in the South-East of England, requiring the fabrication and delivery of 695 units.

3. Project $3-$ a Building Schools for the Future scheme project in the South-East of England, requiring the fabrication and delivery of 369 units.

4. Project 4 - a small hospital project in the South-West of England, requiring the fabrication and delivery of 72 units.

These four projects were selected because they spanned the rollout of a new BIM-based workflow system, and as such would provide a good opportunity for comparison, since Projects 1 and 2 would not be utilising the new BIM-based workflow, whilst Projects 3 and 4 would. The window during which data was collected was just after Project 1 was completed, with all units prefabricated and delivered. Projects 2, 3, and 4 were "live" during data collection, with production and delivery on-going as weekly information flow logs were exported. The figures for precast units quoted above give an indication of the scale and complexity of the four projects; all four were public sector projects of moderate complexity and stakeholder team sizes, with Project 4 significantly smaller than Projects 1,2 and 3. The four projects selected form only a part of the total operational activity of the facility.

Four primary information systems were analysed;

1. Email - general communications,

2. Asite - storage and transfer of design, commercial and planning information,

3. SAP - for transfer and storage of commercial information, used internally only,

4. PPManager - new BIM-based information management and co-ordination tool under continuing development by Nemetschek, for the management and transfer of design and planning information through the building model.

While other information flows were present within the facility (telephone calls, printed documents and faceto-face discussion), the four primary flows above form the foundation for the majority of information exchange, and as such provide as near to a comprehensive view of the information workflows as is possible. A comprehensive study would quantitatively analyse the entire information flow through the facility, through all channels, but time and resourcing constraints made this unrealistic. 
Peter Demian \& David Walters (2013): “The advantages of information management through building information modelling", Construction Management and Economics, DOI:10.1080/01446193.2013.777754

Email remains a popular medium, despite the appearance of new technologies for information and document exchange in construction. Many construction projects use an extranet to address the problems of version control and co-ordination inherent in email. Asite is such an extranet system, whereby project participants have controlled access to a central repository of project documents and project workflow forms over the Internet. SAP is an enterprise application software package used to manage enterprise information internally; in the projects studied for this research, SAP was used primarily to manage commercial information such as cost estimates, formal price quotations, commercial approval documents and formal order forms. PPManager (Precast Part Manager) is an object-oriented system which allows all building information (such as cost data, production and delivery dates) to be linked to objects in the graphical model, driven by an underlying database system. The database operates using a client-server software architecture, allowing views of the central model to be retrieved over the internet. In this sense, PPManager fits within the working definition of BIM adopted here as it is designed specifically to facilitate information flow though models of precast concrete components. The interaction between the four systems (Email, Asite, SAP and PP Manager) was only possible through documents. Report documents could be exported from SAP, PPManager and Asite; these documents could be circulated through email and Asite, or linked to particular components in the PPManager model.

\subsection{Visualising and Measuring Information Flows}

In order to analyse the information flow measurement data in a structured way, a hierarchical information paradigm was utilised (Tribelsky and Sacks, 2010, Tribelsky and Sacks, 2011), in which the fundamental units for measurement are defined. As illustrated in Figure 1, these are:

1. Information Object - A component or constituent part of a building or facility, about which information is being conveyed (e.g. a wall).

2. Information Attribute - 'a technical, engineering or management attribute of an information object such as its dimensions, material type, supplier name, colour, price, etc. The value of an information attribute may appear in any number of information packages.' (Tribelsky and Sacks, 2010)

3. Information Package - A document used for the communication and transfer of information attributes. This includes 2D drawings, spreadsheets, text documents or email exchanges, and 'are the basic units that are transferred between project team members' (Tribelsky and Sacks, 2010). 
Peter Demian \& David Walters (2013): “The advantages of information management through building information modelling", Construction Management and Economics, DOI:10.1080/01446193.2013.777754

4. Information Batch - A collection of information packages transferred by a project participant simultaneously.

5. Project Action - a project participant performs an action in order to communicate information, either specifically to an individual or generally to the entire project.

These definitions were then used to formulate a number of visualisation and measurement tools, allowing characteristic analysis of information flow over time, and at numerous levels of detail.

\section{[INSERT FIGURE 1 ABOUT HERE]}

Table 1 summarises the information flow measurement metrics developed. The action rate allows analysis of the total quantity of information being transferred either over the whole project, between two project events, or between two arbitrary dates. To calculate the action rate between dates $t_{1}$ and $t_{2}$ :

$$
\text { Action Rate }=\frac{\left(N A_{t 1}-N A_{t 2}\right)}{\left(T_{t 1}-T_{t 2}\right)}
$$

Where $N A_{t 1}$ represents the cumulative number of project actions up to date $t_{1}$, and $T_{t 1}$ represents the project week number at date $t_{1}$.

The revision rate is a further extension of the action rate, and expresses the rate at which revised information packages are transferred between two dates;

Revision Rate $=\frac{\left(N R_{t 1}-N R_{t 2}\right)}{\left(T_{t 1}-T_{t 2}\right)}$

Where $N R_{t 1}$ represents the cumulative number of revised information packages transferred up to date $t_{1}$, and $T_{t}$ represents the project day number at date $t_{1}$.

The information iteration metric is a measure of the quantity of revised information packages, in relation to the total number of information packages transferred;

Information Iteration $=\frac{\sum_{i=t_{1}}^{t_{2}} n R P_{i}}{\sum_{i=t_{1}}^{t_{2}} n T P_{i}} \times 100$

Where $n R P_{i}$ represents the number of revised packages transferred on day $i$, and $n T P_{i}$ denotes the total number of information packages transferred on day $\boldsymbol{i}$. It should be noted that this metric includes for 
Peter Demian \& David Walters (2013): “The advantages of information management through building information modelling", Construction Management and Economics, DOI:10.1080/01446193.2013.777754 multiple revisions of the same package; if a revision is issued of a previously revised package, both revised packages are included in the summation.

The systems utilisation metric looks at the relative proportions of information attributes transferred through the four primary information systems;

Systems Utilization $=\frac{\sum_{i=t_{1}}^{t_{2}} n P_{i, k}}{\sum_{i=t_{1}}^{t_{2}} n P_{i_{i} \text { all }}} \times 100$

Where $n P_{i, k}$ denotes the number of information packages transferred on the $i$ th day through system $k$, and $n P_{i}$, allindicates the number of information packages transferred on the $i$ th day through all systems. The information inventory metric measures the time taken for information packages to be used when issued to a team member; it measures the delay in information usage, whereby a higher result indicates poorer flow. This can be measured overall for a project or in relation to a particular team member, whereby the information inventory metric for team member $k$ at time $\boldsymbol{t}$;

$$
\text { Information Inventory }{ }_{, t}=\sum_{j=1}^{n I P_{j}}\left(t-\text { Tup }_{j}\right) \times \mathrm{U}_{\mathrm{j}}
$$

Where $n \boldsymbol{n} \boldsymbol{P}_{j}$ denotes the number of information packages uploaded by time $\boldsymbol{t}, \operatorname{Tup}_{j}$ denotes the time at which package $j$ was uploaded, and $\mathrm{U}_{\mathrm{j}}$ is equal to 1 if package $j$ has not been downloaded or viewed by team member $k ; \mathrm{U}_{\mathrm{j}}=\mathbf{0}_{\text {if }}$ the package has been viewed or downloaded.

The final metric, batching, measures the average size of information batches as defined above. Whilst batching of information is commonplace within the industry, high levels of batching can indicate particularly poor flow, as well as the appearance of bottlenecks. For information system $k$;

Batching $_{, t}=\frac{\sum n I P_{k}}{\sum n P A_{k}}$

Where $n I P_{k}$ indicates the total number of information packages transferred through system $k$, and $n P A_{k}$ represents the total number of project actions carried out through system $k$. 
These metrics form the basis for the measurement of information flows across the four primary information systems and the four projects. Alongside the visualisation measurements described above, they allow comparison between projects as well as assessment of the impact of implementing the PPManager modelbased information management system.

[INSERT TABLE 1 ABOUT HERE]

\section{Results: Analysis of Information Flows}

Semi-structured interviews were conducted in parallel with quantitative data collection and analysis, allowing one to inform the other. Four primary themes emerged, under which headings the subsequent analysis is presented:

1. Information transfer (especially using email),

2. Information storage,

3. Accessibility of information, and

4. Information redundancy.

\subsection{Information Transfer}

In Figure 2, information flow for Project 2 (which did not use PPManager) is visualised at three levels of detail; at the project action level, the information package level and the information attribute level (as defined above), whereby a project action includes one or more information packages, and an information package conveys one or more information attributes. On each chart, the x-axis represents time, against the number of items transferred on the primary y-axis. Information items are aggregated for the SAP, Asite and PPManager and are categorised as either planning, design or commercial. Categorisation was manual, with a small subset re-categorised by a second researcher to ensure validity of categorisation. A secondary bar chart illustrates the number of project emails, providing further context to the information transfer data. (Categorisation of emails transpired to be a practically impossible task because of the volume of emails and the complexity of their contents.) Interviews suggested that these measurements are in line with the perceived flows, but also highlight a number of undesirable phenomena.

[INSERT FIGURE 2 ABOUT HERE] 
Peter Demian \& David Walters (2013): “The advantages of information management through building information modelling", Construction Management and Economics, DOI:10.1080/01446193.2013.777754

It is evident that the programme is being used as a 'live' tracking tool. Planning actions took the form of updating the project programme document and circulating it using Asite. The planning line in the project actions chart in Figure 2 suggests that the project programme document was revised 10 times a week during the production phase, involving the repeated transfer of one information package, containing a large number of information attributes. Analysis of Asite data shows that the project programme has seen 129 revisions, and 199 downloads. The Action Rate metric reflects this, with a value of 11.2 planning packages transferred per week during the production phase. This practice was corroborated through the interviews, and creates challenges in access and interpretation of information, since large quantities of information are repeatedly transferred; this is manifested in an increase in email traffic to aid interpretation.

Further data analysis demonstrates how the use of PPManager mitigates against this undesirable information transfer process. Figure 3 compares the transfer of planning information attributes during the production phases of Project 1 (without PPManager) and Project 3 (with PPManager).

\section{[INSERT FIGURE 3 ABOUT HERE]}

Project 1 shows a dumbbell curve of $i$ transfer over the production phase; at its peak, the project participants were transferring nearly 90,000 information attributes in a week, with a weekly action rate for planning packages of 9.65. This suggests that for Project 1, the programme was being revised twice a day. Such huge data transfer is both largely redundant and difficult to access. There seems to be a rough correlation between the flow of planning information through email and that through the other information systems (for Project 1, this was predominantly Asite, but also included nominally SAP). This implies that uploading an updated programme to Asite lacked richness, and necessitated supplemental email communication to provide context and rationale to this exchange of information attributes.

Project 3 used PPManager to distribute the majority of its planning data; after an initial large generation of data, day-to-day changes were reflected within a 'live' planning view of the PPManager model accessible by all users. This greatly improves information visibility, and drastically reduces the amount of redundant information flow, and hence the amount of time spent searching and retrieving information. In Project 3 , the absolute quantities of information flow (through both PPManager and email) are much smaller, and there is 
Peter Demian \& David Walters (2013): "The advantages of information management through building information modelling", Construction Management and Economics, DOI:10.1080/01446193.2013.777754

a weaker correlation between the two. When comparing absolute values of information flow, it must be noted that the projects differed slightly in scale (with Project 1 requiring delivery of 795 precast units, compared to 369 units for Project 3).

\subsection{Email for Information Transfer}

Contradicting impressions of email were inferred from the qualitative and quantitative data. Interviewees felt that email was incorrectly and over-used, but measurement data suggests it is a highly relied upon tool; a total of 3,322 emails were recorded across four projects, with a peak of 160 emails for one project within a week.

It is hypothesised that the use of PPManager on a project increases the ease with which information is transferred, thereby causing a drop in the use of and reliance on email. This hypothesis was supported by the interviews, and theoretically manifests itself through a reduction in the systems utilisation metric for email, and a corresponding drop in the number of planning-related emails.

Figure 4 displays the systems utilisation metric calculated using the equation given above, for the four projects and systems. Projects 3 and 4 see a significant drop in the use of Asite, as the majority of the planning and design information previously transferred through Asite is now maintained in PPManager; but a drop of between $1 \%$ and $6 \%$ can be seen in the use of email between those projects using PPManager, and those that did not. Analysis of email data showed there was no discernible change in the number of planning-related emails transferred, thereby not supporting the hypothesis. This is possibly caused by a 'legacy effect' of the recent implementation of PPManager, since users were not yet entirely comfortable with the new system.

The average size (in megabytes) of email messages dropped by $30 \%$ in those projects utilising PPManager. This could be a reflection of reduced reliance on email to transfer large files, but could equally reflect differences in project size and scope; it cannot therefore confirm or disprove the above hypothesis.

[INSERT FIGURE 4 ABOUT HERE] 
Peter Demian \& David Walters (2013): “The advantages of information management through building information modelling", Construction Management and Economics, DOI:10.1080/01446193.2013.777754

The quantitative data indicated a significant shift away from Asite and towards PPManager, as shown in Figure 4. Interviewees noted a number of benefits associated with this change, most notably including a reduction in the 'significant amount of administration' associated with using Asite for information storage, as well as an easing of document control-related problems. Interviewees noted that Asite 'can only cope with quite a small number of file types', inhibiting its use for storage of files of certain proprietary formats.

Interviewees noted document control as a central benefit of PPManager. A significant difference between PPManager and Asite as information management tools is the storage structure they each employ. Whilst Asite uses a folder and file metaphor, all PPManager data is linked to the building model. Since many issues relating to use of incorrect or outdated information stem from information storage problems, the fact that PPManager minimises the opportunity for human error helps to reduce these problems. Interviewees noted that the current use of spreadsheets for planning information is 'prone to human error', suggesting that PPManager could take away half of all spreadsheet-based work.

\subsection{Accessibility of Information}

Interviewees observed that the greatest benefits of PPManager pertained to issues of accessibility. Analysis of planning data for Projects 1 and 2 showed that a total of 28 hours and 15 minutes had been spent editing the two programme spreadsheets, with between 22 and 33 minutes spent on each revision. During this time, other project participants could not view the latest project information; considering that the documents were viewed a combined total of 453 times, by up to 16 different project participants, there is a reasonable chance that a project participant made use of incorrect or out-dated information. The key problem with this practice however, is the difficulties involved in accessing and interpreting a package containing up to 5,000 information attributes. By contrast, all interviewees praised the interface employed by PPManager as a significant improvement compared to document-based information management. PPManager utilises the building and unit models to convey all information. A further benefit noted by interviewees was the depth of available information. Whilst the document-based system only allows access to those information attributes stored within each document, the model-based system utilised by PPManager means that all design and planning information attributes related to a particular unit are accessible within a single view. 
Peter Demian \& David Walters (2013): "The advantages of information management through building information modelling", Construction Management and Economics, DOI:10.1080/01446193.2013.777754

\subsection{Information Redundancy}

Table 2 shows the metrics relevant to information redundancy calculated for the four projects. The projects showed comparable action rates, with the relative differences in action rate corresponding roughly to the differences in scale between the four projects (i.e. the number of precast units to be delivered for each project). With regards to project revision rates data, whilst all projects showed a similar information iteration metric, Projects 1 and 2 showed a higher revision rate during the production phase. This observation could be caused by the change in process associated with PPManager; interviewees noted a contrast between the 'hand to mouth' approach used before PPManager and the more timely access to data possible when using PPManager. Interviewees discussed the increased emphasis on earlier and accurate project data brought about by PPManager. This observation is manifested in the reduced in revision rates during the later stages of Projects 3 and 4.

\section{[INSERT TABLE 2 ABOUT HERE]}

Calculation of the information inventory metrics using Asite data allows inferences to be drawn regarding the speed and demand for information flow within a project. The data suggests that information did not flow fast enough for downstream receivers, particularly within the production project phase; this observation was corroborated through interviews. Since Projects 3 and 4 did not make use of Asite in such a way, it was not possible to draw conclusions regarding the benefits PPManager confers within this area.

A final interpretation of information redundancy concerns 'positive redundancy', or backup systems. It was noted by an interviewee that the extent and availability of the data stored on PPManager would cause significant problems if the system became unavailable, and the quality and availability of backup systems is in no way clear.

\subsection{Comparability of Project Case Studies}

The level of comparison between the four case study projects is constrained by the relative scope and size of each; whilst the total quantity of information packages increases with the number of units to be fabricated, the core process requirements applied to each project also lead to the generation of a significant quantity of information packages unrelated to the project's size. Therefore the number of information attributes only 
Peter Demian \& David Walters (2013): “The advantages of information management through building information modelling", Construction Management and Economics, DOI:10.1080/01446193.2013.777754

loosely correlates to the project size, with additional influences such as the wider project nature and complexity also contributing to the information flow characteristics.

\section{Conclusions}

The problems found in typical information management systems applied to building construction projects have been pinpointed through measurement and visualisation of information flow, and correlated with interview data. Whilst the benefits and challenges of implementing a BIM-based solution in such projects have been identified qualitatively, it was only possible to measure some (but not all) of these benefits and challenges. The following conclusions can be drawn:

- For the time being, email is irreplaceable (from the data presented in Figures 2, 3 and 4). Given the documented shortcomings of email, more research is needed to identify the flaws in alternative information systems which prevent them from replacing email.

- A document (as an information package) is too coarse a grain of information to be exchanged, actioned and revised. This is evident from Figure 3 and the observed practice of updating the project programme by revising and circulating the project programme document.

- The construction extranet stands to benefit the most from aligning information management to the building model. From Figure 4, the introduction of PPManager reduced the use of Asite.

Many of the benefits identified here aligned with those reported in literature, notably including accessibility and interpretation of large volumes of construction information. Taken in unison, the measurement of information flows highlighted a number of key underlying trends. The BIM-based solution helped to foster more accurate, on-time and appropriate exchange of information between project participants, as well as promoting earlier creation of critical information relating to design detailing, programming, logistics and coordination that help to generate significant value during the later production phases. These underlying trends were noted by the interviewees, and highlight the core potential of BIM as a mechanism by which to foster significantly greater collaboration between project participants, thus placing considerable emphasis on its role in 'a human activity that ultimately involves broad process changes in construction' (Eastman, et al. 2008). 
Peter Demian \& David Walters (2013): “The advantages of information management through building information modelling", Construction Management and Economics, DOI:10.1080/01446193.2013.777754

Of course caution must be exercised when interpreting and generalising the results reported here. The four construction projects studied represent a particular type and scale of project: medium scale, public sector projects. The volume of information traffic would be greater in larger scale projects, as would the importance of systems to manage this information. The results presented here imply that BIM (in the form of PPManager) is appropriate for projects of a relatively small scale, and this agrees with some other research (Sebastian 2010); however, it is to be expected that the information management advantages might be more significant for larger scale projects (Aranda-Mena et al., 2008). PPManager is only applicable to precast concrete construction. The developers of that system do not prominently label it as a "BIM" platform, even though it clearly appears to strive for integrated information management.

The use of PPManager was championed by the fabrication facility; the use of Asite and SAP was supported by the general contractor. The use of email was of course universal. The combined use of the different media, and the changes in information flow reported here, were only possible because of the close relationship between the general contractor and its subsidiary, the fabrication facility. Considered collectively, the four systems monitored for information flow offer a reasonable representation of the full range of information management systems. However those four systems played limited and distinct roles in the projects studied, and it must be acknowledged that information will have been communicated through other media as well, particularly informal media.

The research reported here paves the way for future research on measuring information flows and the value of linking information do the graphical building model. Humans possess special cognitive strengths in processing visual information: a fuller exploitation of those strengths can have fundamental implications for the design of future BIM systems. 
Peter Demian \& David Walters (2013): “The advantages of information management through building information modelling", Construction Management and Economics, DOI:10.1080/01446193.2013.777754

\section{References}

Abukhder, J. and Munns, A.K. (2005) 'Attributing Management Problems on Construction Projects to Project Information', 19th Annual ARCOM Conference, Association of Researchers in Construction Management, pp. 543-552.

Anumba, C.J., Pan, J., Issa, R.R.A. and Mutis, I. (2008) 'Collaborative project information management in a semantic web environment', Engineering, Construction and Architectural Management 15(1) 1-17.

Aranda-Mean, G., Crawford, J., Chevez, A. and Froese, T (2008) 'Building Information Modelling Demystified: Does it Make Business Sense to Adopt BIM?', paper presented at CIB W78 conference, IT in Construction in Santiago, Chile.

Björk, B. and Laakso, M. (2010) 'CAD standardisation in the construction industry--A process view', Automation in Construction 19(4) 398-406.

Dawood, N., Akinsola, A. and Hobbs, B. (2002) 'Development of automated communication of system for managing site information using internet technology', Automation in Construction 11(5) 557-572.

stman, C. and Sacks, R. (2008). "Relative Productivity in the AEC Industries in the United States for On-Site and Off-Site Activities." J. Constr. Eng. Manage., 134(7), 517-526.

Eastman, C.M., Teicholz, P., Sacks, R. and Liston, K. (2008) BIM Handbook: A guide to building information modeling for owners, managers, designers, engineers, and contractors. New Jersey, USA: Wiley Publishing.

Fellows, R., Liu, A, (2003). Research Methods for Construction. 2nd ed.. 2003.

Fisher, N. and Li Yin, S. (1992) Inforamation Management in a Contractor: A Model of The Flow of Project Data, London: Thomas Telford.

Fitzgerald B and D Howcroft (1998). "Competing dichotomies in IS research and possible strategies for resolution." ICIS '98: Proceedings of the international conference on Information systems, pp 155164, Association for Information Systems Atlanta, GA.

Fox, S. and Hietanen, J. (2007) 'Interorganizational use of building information models: potential for automational, informational and transformational effects', Construction Management and Economics 25(3) 289-296.

Gallaher, M.P., O'Conor, A.C., Dettbarn, J.L. and Gilday, L.T. (2004) 'Cost Analysis of Inadequate Interoperability in the U.S. Capital Facilities Industry', National Institute of Standards \& Technology, Aug, 1-210. 
Peter Demian \& David Walters (2013): “The advantages of information management through building information modelling", Construction Management and Economics, DOI:10.1080/01446193.2013.777754

Giel, B., Issa, R.R.A. and Olbina, S. (2010) 'Quantitative Benefits of Building Information Modeling Measured in Construction', Proceedings Innovation in AEC, Penn State, University Station, June 9-11 2010

Goedert, J. and Meadati, P. (2008) 'Integrating construction process documentation into building information modeling', Journal of Construction Engineering and Management 134(7) 509-516.

Grilo, A. and Jardim-Goncalves, R. (2010) 'Value proposition on interoperability of BIM and collaborative working environments', Automation in Construction 19(5) 522-530.

Hendrickson, C. and Au, T.(2003) Project Management for Construction: Fundamental Concepts for Owners, Engineers, Architects and Builders, $22^{\text {nd }}$ edition, Pittsburgh: Prentice Hall.

Hicks, B. (2007) 'Lean information management: Understanding and eliminating waste', international Journal of information Management 27(4) 233-249.

Howell, G.A. (1999) 'What is Lean Construction - 1999', Seventh Annual Conference of the International Group for Lean Construction, Berkeley, CA.

Huang, T., Li, H., Guo, H., Chan, N., Kong, S., Chan, G. and Skitmore, M. (2009) 'Construction virtual prototyping a survey of use', Construction Innovation 9(4) 420-433.

Jacobsson M, HCJ Linderoth (2010). "The influence of contextual elements, actors' frames of reference, and technology on the adoption and use of ICT in construction projects: a Swedish case study." Construction Management and Economics 28(1) 13-23.

Jacobsson M, HCJ Linderoth (2012). "User perceptions of ICT impacts in Swedish construction companies: 'it's fine, just as it is'". Construction Management and Economics 30(5), 339-357.

Krygiel, E., Nies, B. and McDowell, S. (2008) Green BIM: successful sustainable design with building information modeling, Indianapolis: Wiley Publishing.

Lee, G., H. K. Park, J. Won. "D3 City project - Economic impact of BIM-assisted design validation." Automation in Construction, 22 (March 2012), Pages 577-586

Li, H., Guo, H.L., Skitmore, M., Huang, T., Chan, K.Y.N. and Chan, G. (2011) 'Rethinking prefabricated construction management using the VP-based IKEA model in Hong Kong, Construction Management and Economics 29(3), 233-245.

Leicht, R. and Messner, J. (2008) 'Moving toward an 'intelligent' shop modeling process', IT in Construction 13, 286-302, Available: http://www.itcon.org/2008/20

Mahalingam, A., Kashyap, R. and Mahajan, C. (2010) 'An evaluation of the applicability of 4D CAD on construction projects', Automation in Construction 19(2) 148-159. 
Peter Demian \& David Walters (2013): “The advantages of information management through building information modelling", Construction Management and Economics, DOI:10.1080/01446193.2013.777754

Marshall-Ponting, A. and Aouad, G. (2005) 'An nD modelling approach to improve communication processes for construction', Automation in Construction 14(3) 311-321.

Nemetschek (2010) Nemetschek PPManager, [Online], Available: http://www.scia-online.com/en/PPmanager.html [28 November 2010].

Pena-Mora, F., Vadhavkar, S., Perkins, E. and Weber, T. (1999) 'Information Technology Planning framework for large-scale projects', Journal of Computing in Civil Engineering 13(4) 226-237.

Pries, F. and Janszen, F. (1995) 'Innovation in the Construction Industry: the dominant role of the environment', Construction Management and Economics 13, 43-51.

Reichstein, T., Salter, A. and Gann, D. (2005) 'Last among equals: a comparison of innovation in construction, services and manufacturing in the UK', Construction Management and Economics 23(6)631-644.

Rischmoller, L., Fischer, M., Fox, R. and Alarcon, L. (2001) '4D planning and scheduling (4D-PS): grounding construction IT research in industry practice', paper presented at CIB W78 Conference, IT in Construction in Mpumalanga, Africa.

Sacks, R., Koskela, L., Dave, B., and Owen, R. (2010). "Interaction of Lean and Building Information Modeling in Construction." J. Constr. Eng. Manage., 136(9), 968-980.

Sebastian R (2010). “Integrated Design and Engineering using Building Information Modelling: A Pilot Project of Small-Scale Housing Development in The Netherlands," Architectural Engineering and Design Management, 6:2, 103-110.

Sexton, M. and Barrett, P. (2003) 'A literature synthesis of innovation in small construction firms: insights, ambiguities and questions', Construction Management and Economics 21(6) 613-622.

Shim, C.S., Lee, K.M., Son, W.S. and Moon, J.W. (2008) 'Collaborative Design of High-speed Railway Lines using 3D information models', paper presented at IABSE Conference, IABSE in Helsinki, Finland.

Slaughter, E.S. (1998) 'Models of construction innovation', Journal of Construction Engineering and Management 124(3) 226-231.

Teicholz P (2001) "U.S. Construction Labor Productivity Trends, 1970-1998." Journal of Construction Engineering and Management, September/October 2001, pp.427-429.

Tribelsky, E. and Sacks, R. (2010) 'Measuring information flow in the detailed design of construction projects', Research In Engineering Design 29(3) 189-206. 
Peter Demian \& David Walters (2013): “The advantages of information management through building information modelling", Construction Management and Economics, DOI:10.1080/01446193.2013.777754

Tribelsky E. and Sacks R (2011): "An Empirical Study of Information Flows in Multidisciplinary Civil

Engineering Design Teams using Lean Measures." Architectural Engineering and Design Management, 7(2) 85-101.

Winch, G. (2003) 'Models of manufacturing and the construction process: the genesis of re-engineering construction', Building Research \& Information 31(2) 107-118.

Womack, J.P., Jones, D.T. and Roos, D. (1990) The machine that changed the world, Toronto: Collier Macmillan. 
2

\begin{tabular}{lll} 
Metric & Description & Units \\
\hline Action Rate & Rate of information transfer & Actions/Time \\
\hline Revision Rate & Rate of revision transfer & Revisions/Time \\
\hline Information Iteration & Proportion of revised information & Percentage \\
\hline Systems Utilisation & $\begin{array}{l}\text { Proportion of packages transferred through } \\
\text { each information system }\end{array}$ & Percentage \\
\hline Information Inventory & $\begin{array}{l}\text { The number of available but unused } \\
\text { information packages }\end{array}$ & Information packages \\
\hline Batching & $\begin{array}{l}\text { Average number of packages transferred } \\
\text { simultaneously }\end{array}$ & Information packages
\end{tabular}

Table 1: Information flow measurement metrics 


\begin{tabular}{|c|c|c|c|c|c|c|}
\hline Metric & Description & Units & $\begin{array}{l}\text { Project } \\
1\end{array}$ & $\begin{array}{l}\text { Project } \\
2\end{array}$ & $\begin{array}{l}\text { Project } \\
3\end{array}$ & $\begin{array}{l}\text { Project } \\
4\end{array}$ \\
\hline Action Rate & $\begin{array}{l}\text { Rate of information } \\
\text { transfer }\end{array}$ & Actions/Time & 62,3 & 75.1 & 25.0 & 16.5 \\
\hline $\begin{array}{l}\text { Revision } \\
\text { Rate }\end{array}$ & Rate of revision transfer & Revisions/Time & 6.9 & 13.5 & 0.8 & 2.4 \\
\hline $\begin{array}{l}\text { Information } \\
\text { Iteration }\end{array}$ & $\begin{array}{l}\text { Proportion of revised } \\
\text { information }\end{array}$ & Percentage & $11 \%$ & $18 \%$ & $3 \%$ & $14 \%$ \\
\hline \multirow[t]{2}{*}{$\begin{array}{l}\text { Information } \\
\text { Inventory }\end{array}$} & $\begin{array}{l}\text { The average number of } \\
\text { available but unused } \\
\text { information packages }\end{array}$ & $\begin{array}{l}\text { Information } \\
\text { Packages }\end{array}$ & 5.2 & 21.0 & N/A & N/A \\
\hline & $\begin{array}{l}\text { The average number of } \\
\text { days taken to complete } \\
\text { an action }\end{array}$ & Days & 3.1 & 2.3 & N/A & N/A \\
\hline
\end{tabular}

Table 2: Metrics related to information redundancy 


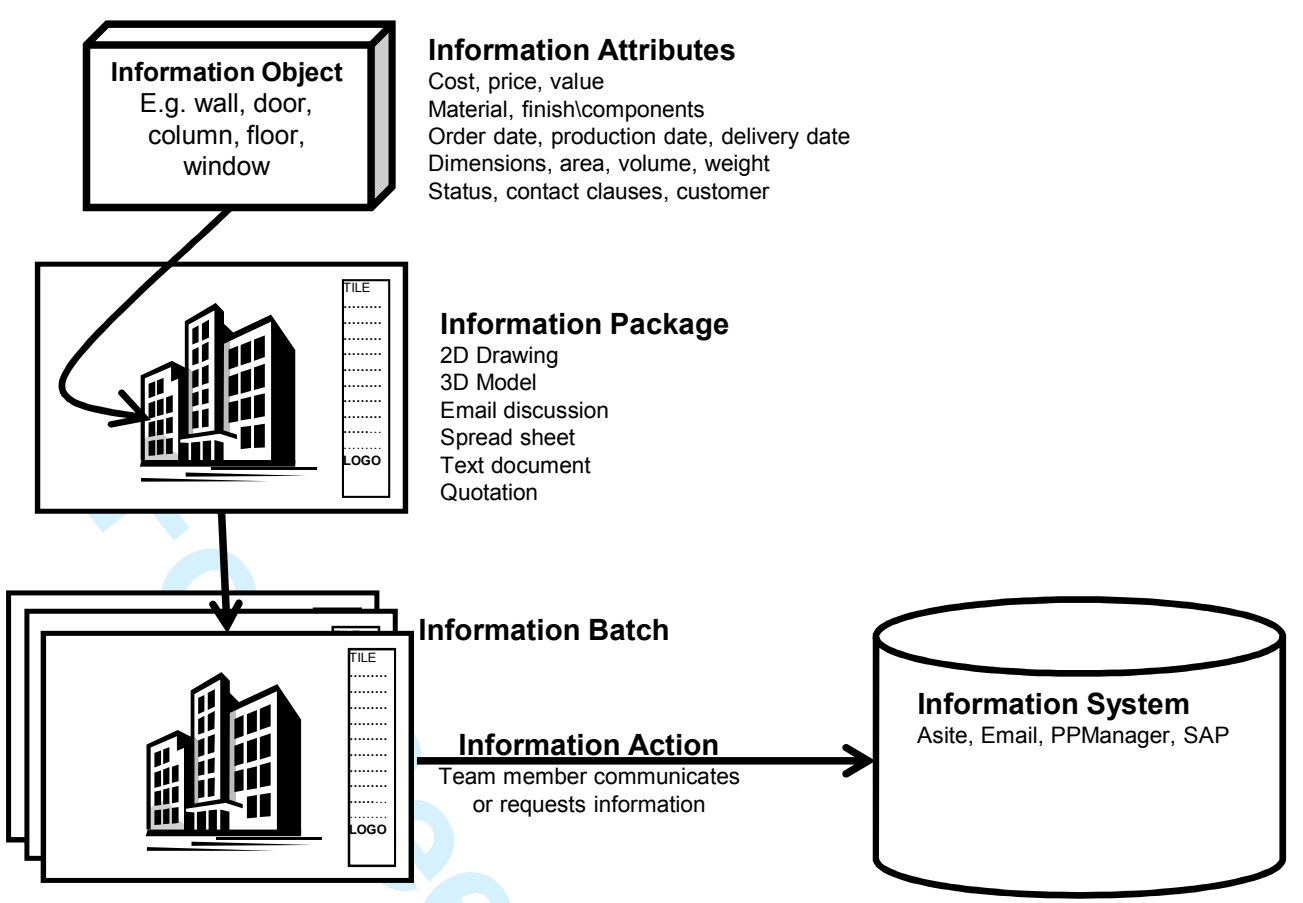

Figure 1 - Illustration of the defined terms 

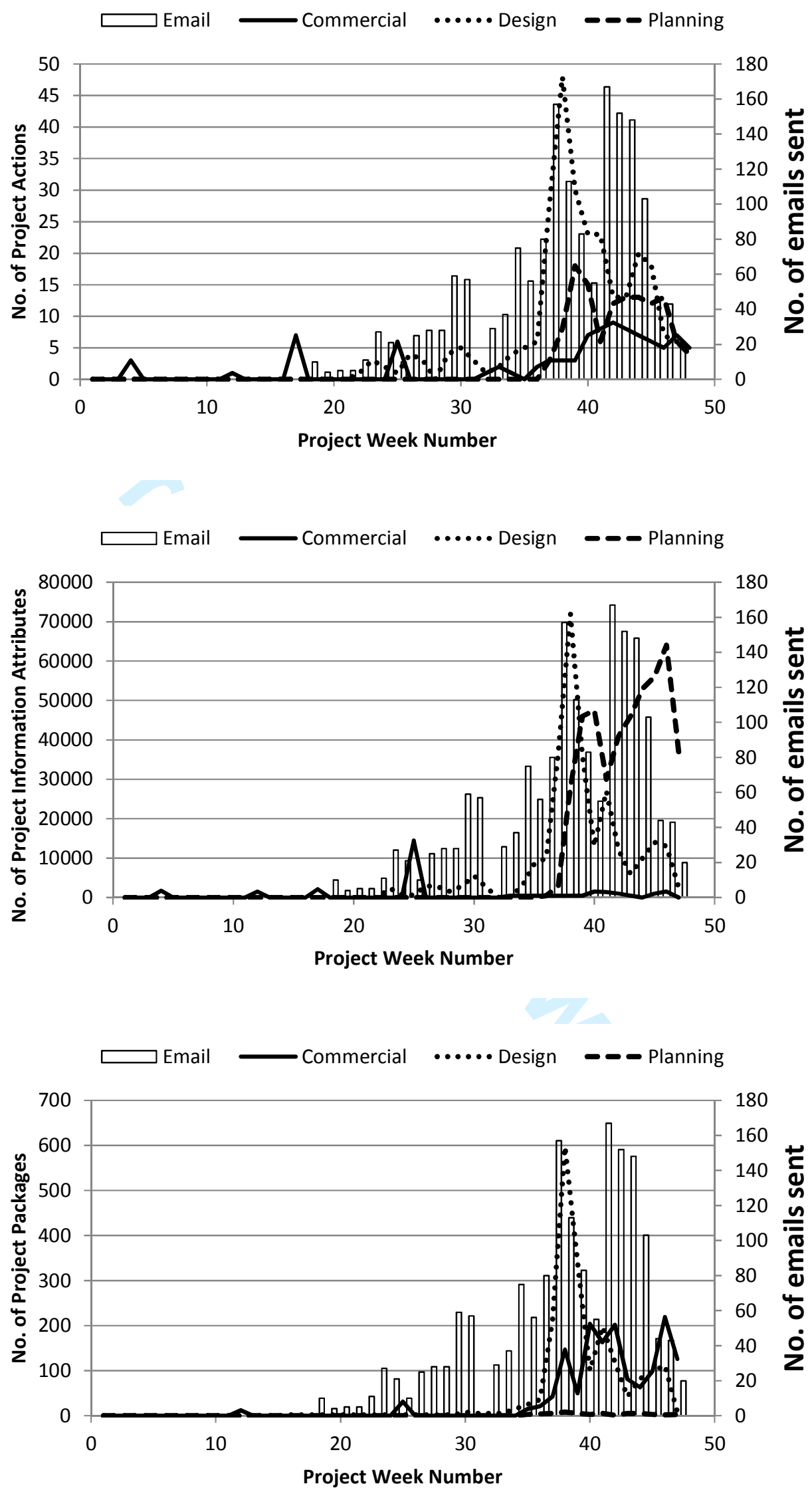

Figure 2 - Information flows for Project 2 (without PPManager) measured by Project Actions (top), Project Packages (middle) and Information Attributes (bottom) 
Project 1 (without PPManager)

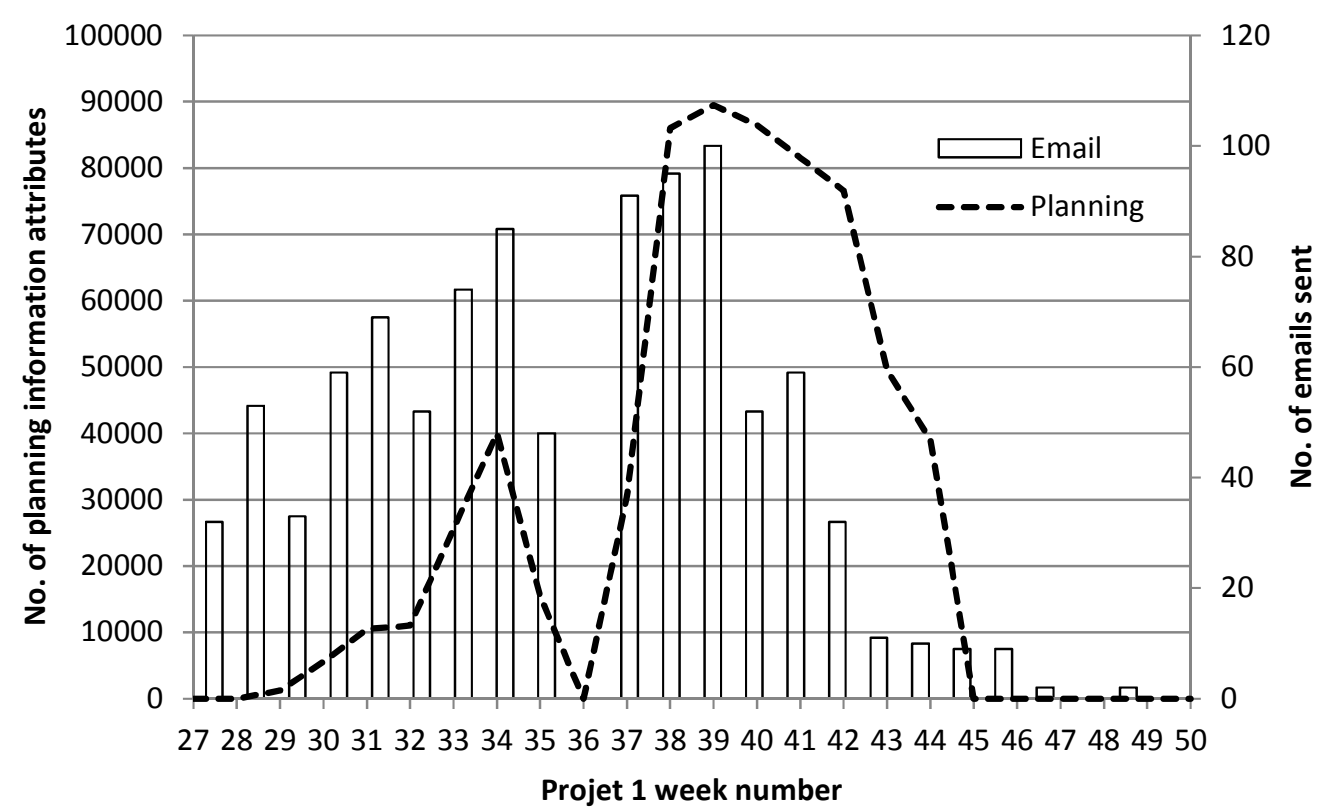

\section{Project 3 (with PPManager)}

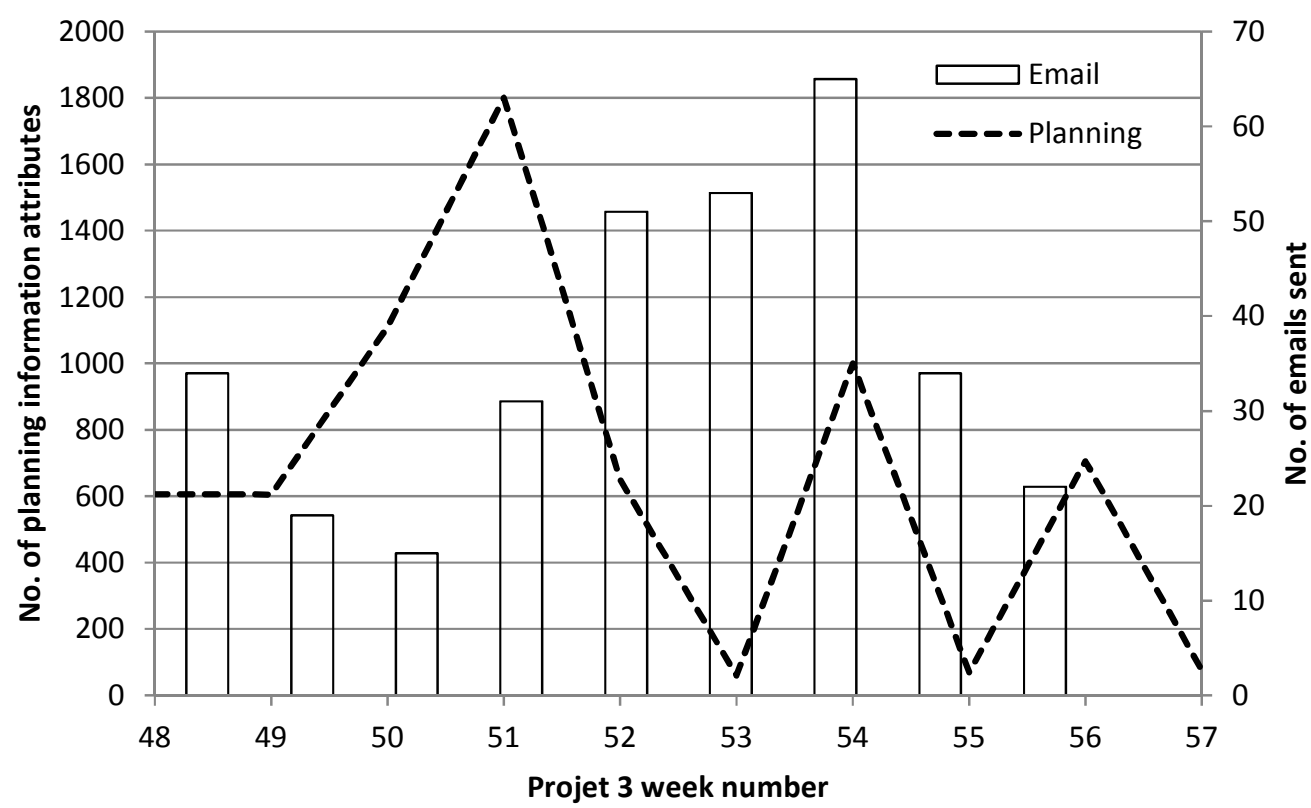

Figure 4 - Planning information attributes transferred during the production phase - Projects 1 and 3 


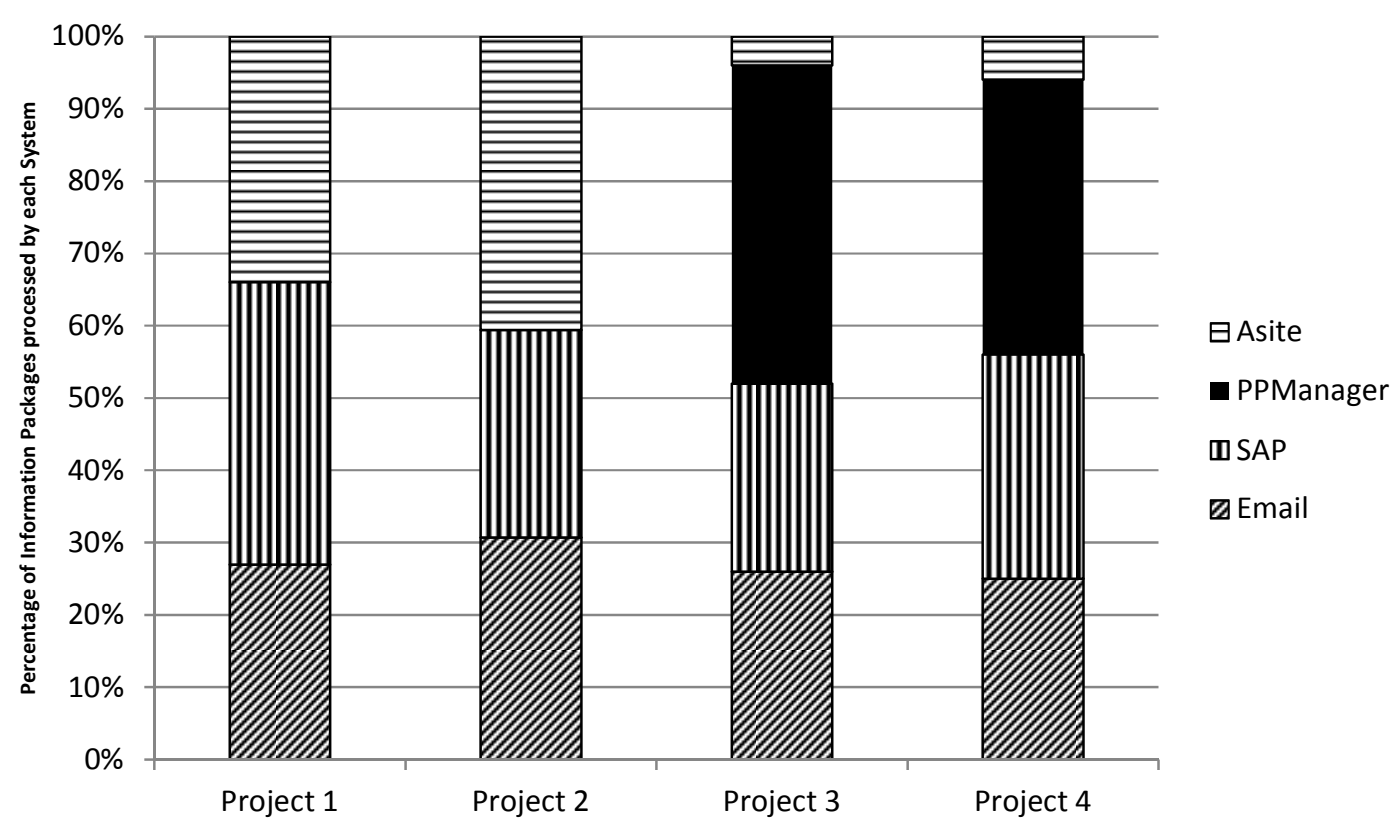

Figure 4-Information Systems Utilisation in Projects 1, 2, 3 and 4 